\title{
College Students' Attitudes \& Responses Toward The Current Economy And Its Implications For Marketing Managers
}

\author{
Lauren Gray, Southeastern Louisiana University, USA \\ Michelle Lamanette, Southeastern Louisiana University, USA \\ Alberto Silva, Southeastern Louisiana University, USA \\ Michael C. Budden, Southeastern Louisiana University, USA
}

\begin{abstract}
Since the early months of 2009, the undeniable woes of the economy are being felt by many. With a record number of corporate closings, rising unemployment and the crises in the financial markets, this may prove to be a difficult year for many. This paper uses empirical evidence collected from Southeastern Louisiana University students to learn how the college community is responding to the current economy, their attitudes toward it, and their outlook toward the future. Furthermore, this paper explores how college students' spending and lifestyles have been affected by the recession. The most important findings of the research indicate that college student spending has not been greatly impacted by the current economy, but there are trends in which marketers need to take note.
\end{abstract}

Keywords: Economy, Recession, College Student, Marketing, Spending

\section{INTRODUCTION AND LITERATURE REVIEW}

ith more than $\$ 237$ billion per year in spending power college students make up a respectable percentage of total U.S. spending power (Sass, 2008). For this reason they are an extremely valuable and important segment of the marketable population. During times of economic recession marketers are not letting any opportunity to elicit new or repeating customers pass them by. According to Craft (2009), an economic recession represents a period of economic decline marked by two successive quarters of negative growth in gross domestic product. Furthermore, a recession turns into a depression when it lasts longer than thirty-six months. The U.S. has until January 2011 before that threshold is crossed (Craft, 2009).

The United States has a history of economic recessions and depressions. Some of these are better known than others such as The Great Depression of 1929-1939 and the early 1980's recession. There have been 18 recorded recessions or depressions in the United States since 1807. The formerly mainstream notion that the U.S. recession would be short and shallow; a V-shaped recession with a quick recovery like the ones in 1990-1991 and 2001 is no longer being considered as the current outlook. Instead, the U.S. recession is predicted to be U-shaped; long, deep, and lasting about twenty-four months. It could end up being even longer; an L-shaped, multiyear dilemma (Roubini, 2009).

Many factors contribute to an economy's fall into recession but a major cause is inflation. Inflation refers to a general rise in the prices of goods and services over a period of time. As inflation rises the spending power is reduced. In a time of economic recession consumer spending begins to decrease. As individuals and businesses spend less in an effort to trim costs, the Gross Domestic Product starts to decline. Furthermore, the unemployment rate rises because companies lay off workers to cut costs. Other factors may contribute to a recession as well, such as the real estate sub-prime mortgage crisis. By January 2007, foreclosures continued to climb and by March 31, 2008, 2.04 percent of single-family homes were in foreclosure and 6.35 percent of all mortgages were 
delinquent by 30 days or more. (Crawford and Young, 2009). It is these combined factors which can cause the economy to fall into a recession.

A recession and undoubtedly a depression will affect not only the economy but many stakeholders within that economy. College students are no exception. In fact, college students may be more susceptible to the risks of a recession. As tuition costs and other fees skyrocket, up $439 \%$ since 1980, college is quickly moving off the radar for some Americans (The Economist, 2009a). In addition to rising tuition costs, the cost of living is also increasing. Unfortunately, family wages are not keeping pace at this time (The Economist, 2009b).

This paper discusses how the current state of the economy has affected college students' spending and lifestyles, as well as their attitudes towards the current and future economy. In addition, the paper presents methods marketers can employ to further their efforts and remain competitive in the current market.

\section{SPECIFIC OBJECTIVES}

There are a number of major objectives associated with this study. The first objective was to identify if or how college students' spending habits have changed with the declining economy. Students' defining characteristics that explain differences in spending habits were also studied. Next, attitudes of college students towards the current and future economy were discerned.

\section{METHODOLOGY}

The methodology used to examine this topic was a questionnaire. A convenience sample of college students at Southeastern Louisiana University (Southeastern) was taken. Although this was a convenience sample, it reflects the population of Southeastern students based on race, ethnicity, and age. A pretest of the questionnaire indicated the instrument needed revision. After reviewing and making the necessary changes the final questionnaire was administered. The data from the survey was entered into an Excel spreadsheet then processed through SPSS. The questionnaire contained inquiries pertaining to the individual's demographic information, personal financial information, changes in spending habits, and attitudes towards the current and future economy.

\section{RESULTS AND FINDINGS}

There were 233 questionnaires distributed to and collected from students on Southeastern's campus. The Pearson Chi-Square Test of Independence was used to discern statistically significant relationships between students' responses and specific characteristics of those students. The generally accepted $95 \%$ confidence interval was the guideline for the chi-square test of independence.

The questionnaire was comprised of four sections. The first section of the questionnaire dealt with personal information about the student such as gender, age, income, number of children, marital status, and place of residency among other things. Characteristics of the respondents which are relevant to study are as follows: $63 \%$ female, $37 \%$ male, 92\% of students are twenty-five years of age or younger, 78\% Caucasian, 16\% African American, and 6\% other ethnicities. These demographic results reflect well the 2008 Southeastern Louisiana University student body which states the University's student population is $63.1 \%$ female, $36.9 \%$ male, $91.8 \%$ who are twenty-five years of age or younger, 76.1\% Caucasian, 16.7\% African American, and 7.2\% other ethnicities (Southeastern, 2008).

The next section of the questionnaire analyzed the economy is affect on students' general lifestyles, if any, as well as the effect on specific aspects of a student's lifestyle. These specific aspects included income, hours at work, expenses, savings, and credit card debt.

When evaluating how students' lifestyles have been affected by the economy, results showed that many students $(46 \%)$ believe their lifestyles have been negatively affected. Furthermore, 54\% of students believe their lifestyles have been positively or not at all affected by the state of the economy, with the majority of this group indicating no impact whatsoever. 
Comparisons were then conducted between changes in student lifestyle and specific student characteristics. There was a statistical relationship between change in lifestyle and a student's college classification. As college classification increases, from freshman to sophomore and so forth, the degree to which a student's lifestyle is negatively affected increases. This idea is further supported by the finding that as classification increases it is less likely that a student was not affected at all by the economy. In other words, students closer to finishing school were more likely to report that the economy was negatively impacting them.

Graph 1. Impact of Current Economy on Specific aspects of a Student's Lifestyle

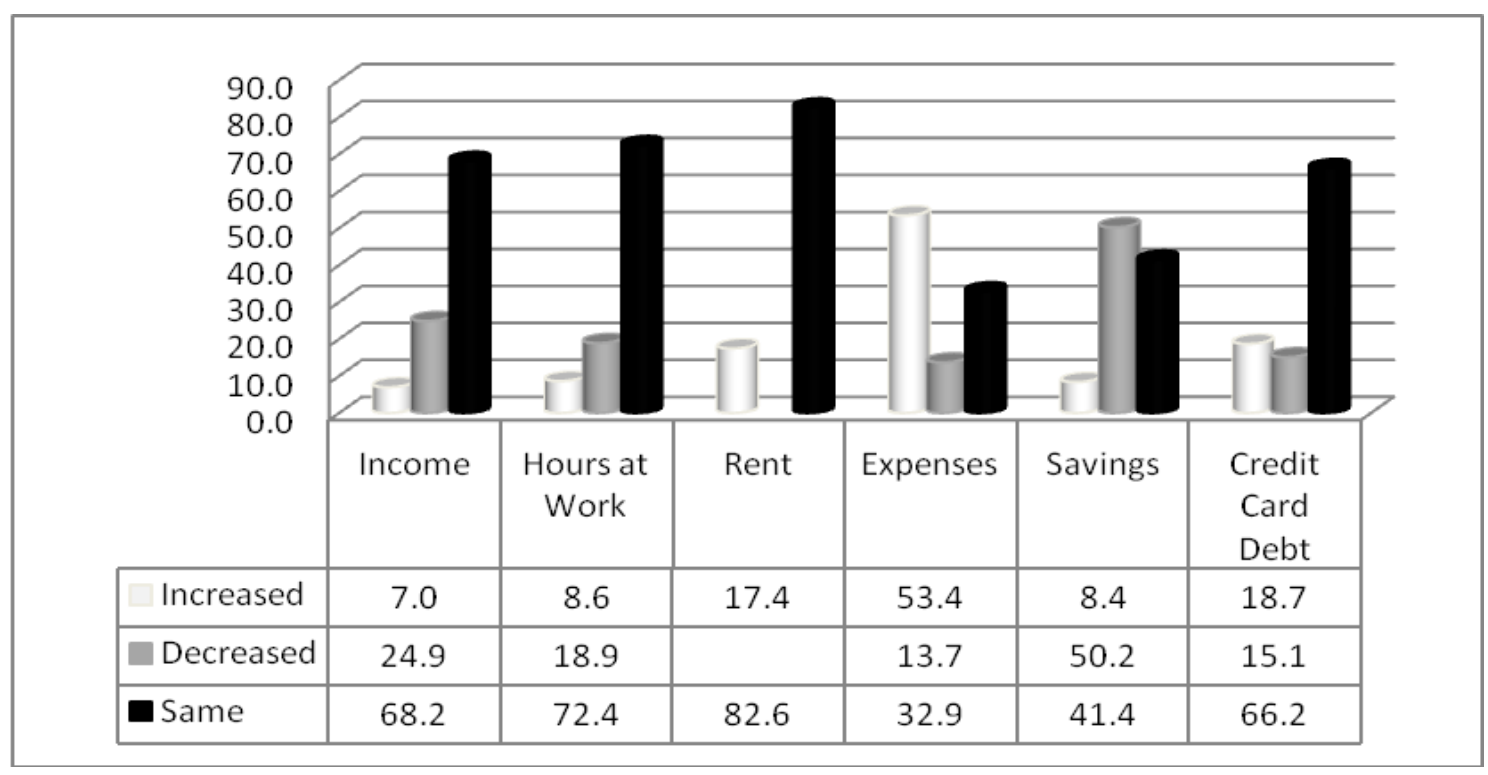

One-quarter of the students surveyed reported a decrease in income and 53\% of students reported an increase in expenses. Although the majority of students savings have decreased it is surprising to find that $49.8 \%$ of students have the same amount of savings or more. This may be due to student fear of the present economy or anticipation of a poor future economy, thus resulting in less spending. Roughly $18 \%$ of the respondents increased credit card debt while $15 \%$ reported a decrease. Also important to note, students reported having the same income, spending the same hours at work, and no change in the rent they pay.

Although debt appears to have remained at nearly the same level some interesting findings with regards to college debt were found. A significant relationship between age and changing credit card debt due to the economy was found. Similarly, a statistically significant link, with a chi-square probability of less than $1 \%$, between college classification and changing credit card debt was discovered. As age and college classification increased so did credit card debt. For students under the age of $21,9.4 \%$ reported an increase in credit card debt due to the current economy. For students ages $21-25,11.6 \%$ reported an increase in credit card debt. Lastly, $25 \%$ of students ages $26-$ 30 reported an increase in credit card debt. An increase in credit card debt due to the economy was reported by 5.9\% of freshman, $9.5 \%$ of sophomores, $13 \%$ of juniors, and $15.5 \%$ of seniors. The trend changes for graduate students. Only $7.9 \%$ of graduate students reported an increase in credit card debt. This may be due to the availability of graduate assistantships from the university which pays tuition as well as an hourly wage. Also, graduate students are able to get more financing from loans than undergraduate students. There is an increasing trend in credit card debt due to the economy as age and classification of students increase. Financial support from family and friends may decrease as age increases, which would be reflected in this finding.

With responses on hand, habits were grouped into three different broad categories: entertainment, restaurants and bars, and other purchases. 
Graph 2. Economy Impacts on Students' Spending Habits

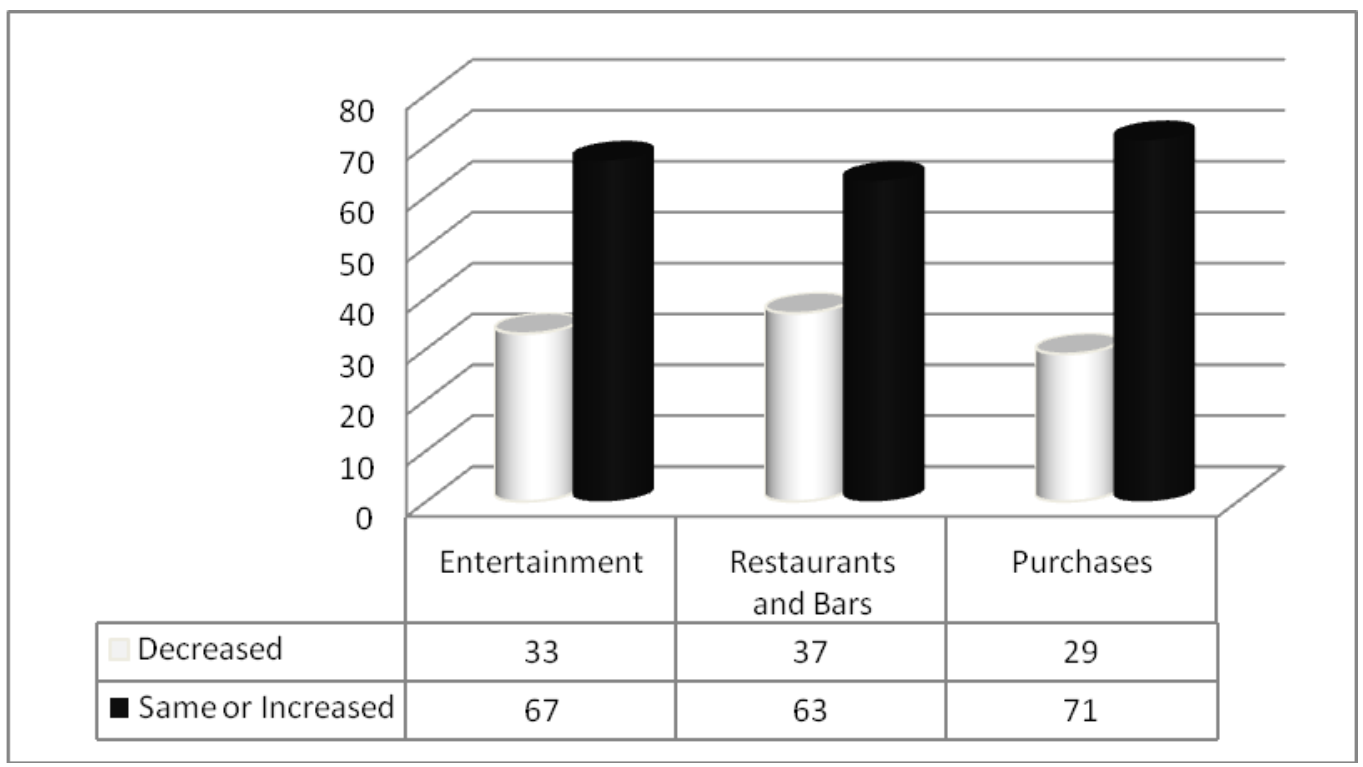

Spending on entertainment, which included movie and music purchases, theaters, concerts and sporting events, spas/salons, vacations, driving mileage and hobbies was studied. Students' responses suggest that the economic downturn is not strongly affecting their entertainment habits (67\% either stayed the same or increased). Eating at full service or fast food restaurants, as well as bar visits was also evaluated. There is not a large change in these categories, with $63 \%$ of students reporting no change in visits to restaurants and bars. In the category of other purchases, the only significant change to note is that brand name purchases have decreased by $40 \%$ while store brand purchases have increased by $30 \%$. Although many students claim their expenses have increased and their savings have decreased, evidence that there is a large change in students' spending habits was not apparent.

Table 1. Expectations about the Economy

\begin{tabular}{|lc|}
\hline Improvement & Percent \\
1 Year or Less & 15.6 \\
1 Year to 2 Years & 37.6 \\
2 Years to 5 Years & 33.5 \\
5 Years or Less & 13.3 \\
Total & 100.0 \\
\hline & Percent \\
\hline Income & 60.9 \\
More Income & 39.1 \\
Same or Less Income & 100.0 \\
\hline Total & Percent \\
\hline & 26.5 \\
\hline Savings & 53.9 \\
Save the same as now & 19.6 \\
Save more than now & 100.0 \\
\hline Not sure or less & \\
Total &
\end{tabular}

As can be seen in the Table 1, improvements in the economy are expected by students in one to five years from now. Results do not vary based on gender, marital status, and number of children. When asked about their 
future income, as Table 1 notes, $61 \%$ of students reported they are expecting higher income in the future. This may be apparent as college students believe they will increase their income upon graduation. In addition, men appear more optimistic than women, with $69 \%$ of men expecting more income within a year, while $44 \%$ of women are expecting the same or less income in the near future.

An important aspect of this study is students' perceptions of the future of the economy. The majority of respondents (35.2\%) believe the economy will improve in one to two years. The next largest percentage of students $(31.3 \%)$ believes the economy will improve in two to five years, while $14.6 \%$ of college students believe it will improve in less than a year. A large portion of students (12.4\%) believe it will take longer than five years for the economy to see an improvement. Only $6 \%$ of students stated that they do not believe the economy will ever improve. Additionally, it is important to note that $54 \%$ of students believe that if/when the economy improves they will save more money than they are saving now, while $26.5 \%$ of respondents will save the same as they do now. Gender and marital status are not influencing factors towards students' expectations about savings, but among students with one or more children, saving appears to be a must. The majority of students (85\%), with one or more children, are expecting to save the same amount of money or more in the future.

Regarding students' sources of income, $60 \%$ of students reported their main source of income was either themselves or their spouse. Among $40 \%$ of students, their main source of income is one of the following: parents, loans, grandparents, or grants. Half of single/unattached students, as well as students with no children independently earn their income. Approximately $72 \%$ of married students obtain their primary income from themselves or their spouse. Many students have one or more sources of secondary income, including themselves, parents, loans, and grants.

\section{CONCLUSION}

Even though the majority of the students reported no change in their lifestyle, engaged and married students were more likely to state that the economy is negatively affecting their lifestyle.

Since students indicate very little change in income, increasing expenses must be covered by savings or debt. Since the majority of students' savings has decreased and credit card debt has increased it would be safe to say the increases in expenses are being covered by either or both savings and debt.

Students' habits seem to be mostly unaffected by the current economy, although some habits show a possible trend. The decrease in brand-name product purchases together with the increase in store-brand purchases suggest that students are getting store-name products to balance the deficit between decreasing incomes and increasing expenses. Students appear to be weathering the economic storm not by spending less, but by shopping more carefully; substituting store-brand products for name-brand products.

Respondents plan to save the same amount of money or more in the future. This behavior can be based on the confidence of earning more money in the future. Students may feel they are going to generate more income in the future and in return they will increase savings. Another possible conclusion could be that students believe when the economy improves their expenses will decrease, thus leading to increased savings. Alternatively, students may now be aware of economic volatility and want to save for a rainy day.

It appears students' lifestyles have not been drastically affected by the current economy although there are a large number of students reporting changes in specific aspects such as savings, expenses, purchasing, and other consumer habits. Students' lifestyles have remained the same because they are using their savings or increasing credit card debt to cover the deficit between their income and their expenses. Also, students could be feeling limited effects of the crisis because this recession is still in its early stages and it has not yet impacted everyone.

In the future, if the economy does not improve, it could generate a huge problem for students and companies alike when savings are depleted or credit card debt becomes too high. Another aspect which can impact student spending is the effect of the economy on students' families or financial providers. This could cause those 
students whose primary source of income is parents or family to be greatly affected. They would have to change spending habits in order to cope with a tightening economy.

\section{MARKETING IMPLICATIONS}

Students appear to be purchasing more store-brand products. This presents an opportunity to promote these products, highlighting the advantages of store brands and their relationship between quality and price.

Our research shows that college student spending on concerts, music, movies, spas, bars, clubs, and other sectors of the entertainment industry are not being affected by the current economy. This is promising news to marketers. This study should help marketers realize where their time, money, and energy need to be invested to garner the best return.

Another area that could be of great interest and should be investigated further is college student's credit card debt. Student credit card debt appears to be on the rise as the economy worsens and students seek to maintain their standard of living. College students need to be aware of the pitfalls of an increasing debt burden on their future and need to be educated on managing their finances. Indeed, Allen and Kinchen (2009) emphasized the importance of universities preparing students to handle their personal finances.

College students are spending less, incurring more debt, saving less and have a slightly negative attitude toward the future of the economy. Marketers and manufactures need to notice this trend and market and produce their products and services accordingly.

\section{LIMITATIONS AND RECOMMENDANTIONS}

One of the limitations of this research is the use of a convenience sample. Only Southeastern students were surveyed.

Furthermore, it is possible that the population surveyed has not been impacted as adversely by the recession as other areas of the country. For example, there have not been major corporate lay-offs in Louisiana at this time, and Louisiana has one of the lowest unemployment rates in the U.S. (Izzo, 2009).

Furthermore, this research is one of the first to look at how the economy is affecting college students. In the future it is recommended that research on the topic, perhaps more in depth in certain areas where statistically significant differences were noted should be conducted in order to compare results and identify trends.

\section{REFERENCES}

1. Allen, Kayla. and Kinchen, Victoria (2009). Financial Practices of College Students. Global Journal of Business Research. 3, 1, p. 105-116

2. $\quad$ Craft, Matthew (2009, March 02). The "D" World. Forbes. 183, 4, p28-29.

3. Crawford, P. and Young, T. (2009). The Credit Crunch" The Roller Coaster Ride Continues. Journal of Business \& Economics Reseacrh. 7, 1, p. 115.

4. Izzo, Phil (2009, March 27). February Unemployment Rates, by State. In WSJ.com. Retrieved March 30, 2009, from http://blogs.wsj.com/economics/2009/03/27/february-unemployment-rates-by-state/.

5. Roubini, Nouriel (2009, January 22). The Worst is Yet to Come. Forbes.com. Retrieved March 20, 2009. From http://www.forbes.com/2009/01/21/bear-market-rally-oped-cx nr_0122roubini.html.

6. Sass, Erik (2008, August 05). College Students Getting Richer, Pickier, Alloy Finds. In mediapost.com. Retrieved February 20, 2009, from http://www.mediapost.com/publications/index.cfm?fa=Articles.showArticle\&art_aid=87917.

7. Southeastern Louisiana University. (2008, Fall). Factbook. In selu.com. Retrieved March 20, 2009 from http://www.selu.edu/admin/ir/factbook/student_info.html.

8. The Economist (2009a, January 22). College on Credit. The Economist. Retrieved March 20, 2009), from http://www.economist.com/world/unitedstates/displaystory.cfm?story id=12903475.

9. The Economist (2009b, March 03). Diagnosing Depression. The Economist,. 390, 8612, p57. 